\title{
Technology and machine parameters for preparing the soil for sowing cotton
}

\author{
Sanjar Toshtemirov ${ }^{1 *}$, Serobjon Mustafayev ${ }^{2}$, Alham Xo'jayev ${ }^{2}$, Isomiddin Mamatkulov $^{1}$ \\ and Farrukh Boboev ${ }^{3}$ \\ ${ }^{1}$ Karshi Engineering Economic Institute, Karshi, Uzbekistan \\ ${ }^{2}$ Karshi branch of Tashkent Institute of Irrigation and Agricultural Mechanization Engineers \\ ${ }^{3}$ Karshi State University, Karshi, Uzbekistan
}

\begin{abstract}
The study aims to justify the design scheme and main parameters of the combined aggregate for soil preparation for cotton sowing on ridges. The authors have developed the technology of soil preparation for cotton sowing on ridges and the aggregate for its implementation. The technology and design scheme of the developed aggregate are presented. The unit consists of a mouldboard deep loosener with a sloping rack and a ridge maker. The basic principles and methods of classical mechanics, mathematical analysis, and statistics were used in this study. The optimum constructive scheme of combined aggregate is grounded. It was established that to provide formation of new ridges instead of existing ones on fields without stems of cotton with the required degree with minimum power consumption working surfaces of inclined deep looseners equipped with mouldboards and rippers should be turned to each other and shifted relative to each other in a longitudinal plane. The formation of ridges to the required degree with minimal energy input is ensured at a width and length of the subsoiler's chisel, respectively 5 and $20 \mathrm{~cm}$, the width of the wing width $21 \mathrm{~cm}$, wing length between 47 and 49 $\mathrm{cm}$, minimum longitudinal spacing between subsoilers $35 \mathrm{~cm}$.
\end{abstract}

\section{Introduction}

Research on creation and application of machines for tillage and preparation of soil for seeding on ridges, study of their performance and justification of parameters, as well as study of processes of interaction of working bodies with soil were carried out by F.Mamatov [1-16], [18-23], [28-29], B.Mirzaev [5-12], [14-21], [23], 28-29] U.Umurzakov [4, 19], N.Aldoshin [3, 10, 11, 19, 20, 24], D.Chuyanov [5, 27], U.Kodirov [6, 24], H.Ravshanov [4-6], [20], [25-26], H.Fayzullaev [25], I.Kurdyumov [31], E.S.Zykin [31-38] and others.

The technologies of preparation of fields without cotton stems for sowing on ridges, currently used in agricultural production of the Republic, have several drawbacks. In particular, the existing technology has a high material and energy intensity, as it consists of several agro-technical activities carried out by separate units. All this leads to lower productivity, excessive compaction of soil, intensive drying, and delayed soil preparation for sowing. Research analysis has shown that when preparing fields for sowing on ridges, improvement of tillage quality, as well as reduction of fuel, labour and other costs, can be

\footnotetext{
* Corresponding author: sanjar_toshtemirov@mail.ru
} 
achieved by applying combined aggregate, carrying out formation of new furrows instead of existing ridges, new ridges instead of existing furrows on fields without cotton stalks.

The study aims to justify the design scheme and main parameters of the combined aggregate for soil preparation for sowing cotton on ridges.

\section{Methods}

The basic principles and methods of classical mechanics, mathematical analysis, and statistics were used in this study.

Based on the analysis of research works and conducted studies, the technology and constructive scheme of the unit for soil preparation for sowing on the ridges have been developed. Patent for invention № IAP 04832 and utility model № FAP 00672 of the Republic of Uzbekistan are protected.

The proposed technology is carried out in the following sequence (Fig.1): simultaneously loosening soil of the side parts of the right ridge of the existing row spacing, deep linear loosening of the bottom layer of the right side of the ridge being formed to a depth of 25-30 cm, turning the top soil layer with 10-12 cm thickness of the existing right ridge to the left - to the right of the middle of the existing ridge and loosening the bottom of the top layer of the right ridge (Fig.1a). Then in this sequence, loosening the soil on the sides of the left ridge of the existing row spacing, deep linear loosening of the bottom layer of the left side of the ridge being formed to a depth of $25-30 \mathrm{~cm}$, turning the top layer of soil with 10-12 cm thickness of the existing left ridge to the right - to the left side of the middle of the existing ridge and loosening the bottom of the top layer of the left ridge (Fig. $1 b$ ) is done. Then the loosened bottom layer of the right and left ridge topsoil is moved to the middle of the existing inter-row on the previously displaced topsoil. As a result, a new ridge with a deeply loosened bottom layer is formed instead of the existing ridge, and a new furrow is formed instead of the existing ridge (Fig.1d).

The working process of the designed unit for implementing the proposed technology is as follows: subsoiler 4 with a tilt leg loosens the soil at the sides of the right ridge, the existing row spacing and deep linear loosening of the bottom layer of the right side of the ridge being formed, its blade 6 cutting the top layer of soil turns it to the left - to the right of the middle of the existing ridge, and ripper 3 loosens the bottom part of the top layer of the right ridge [33-34].

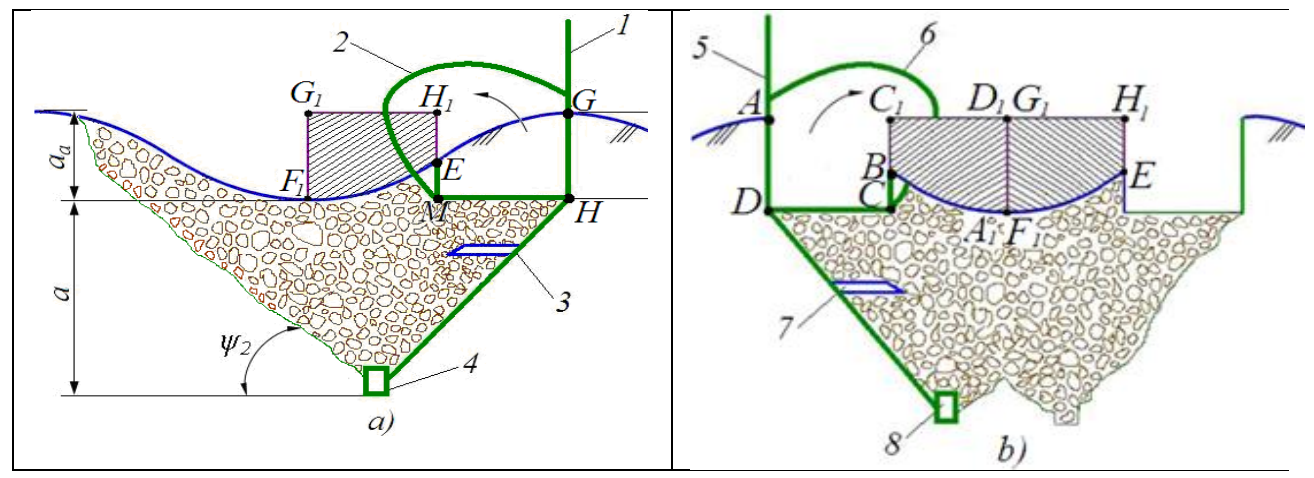




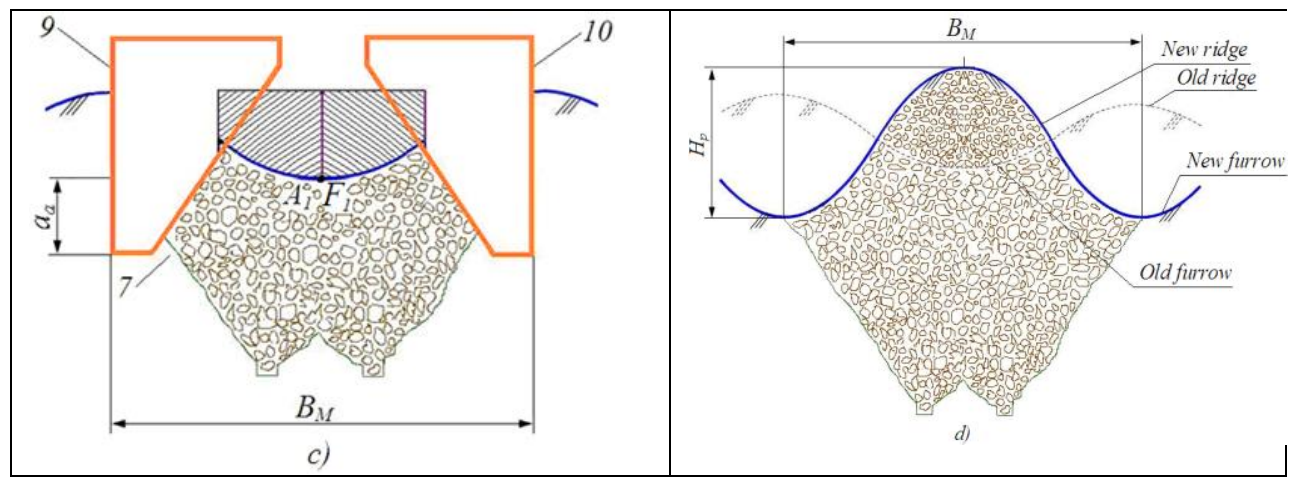

Fig. 1. Process flow diagrams for ridge forming technology in stemless fields

Then deep loosener 5 with tilt stand loosens the soil on the sides of the left ridge of the existing row, and deep linear loosening of the bottom layer on the left side of the ridge being formed, its blade 7 cutting off the top layer of soil turns it to the right - to the left side of the middle of the existing ridge, and loosener 3 loosens the bottom part of the top layer of the left ridge. After that, ridge maker 8 shifts the loosened soil layer of the ridges to form a new irrigation furrow and ridge (Fig.2). The rest of the new ridges and furrows between the rows are formed in the same way [33-34].

To perform the processes of loosening the side of the ridge and the bottom layer of the irrigation furrow, turning the topsoil of the ridge, and loosening its bottom layer, we selected a deep loosener with a sloping stand equipped with a mouldboard and a ripper (Figure 3).

\section{Results and Discussion}

The main parameters influencing the qualitative and energy performance of a deep opener with a sloping machine leg are considered to be the following: $H_{\text {tchk }}$ is height of deep opener, $\mathrm{m} ; b_{i}$ is width of bit, $\mathrm{cm} ; L_{i}$ is length of bit working surface, $\mathrm{m} ; i_{u}$ is angle of bit blade sharpening, degree; $i_{u}$ is angle of bit stand sharpening, degree; $i_{n}$ is angle of blade sharpening, degree; $t_{y}$ and $b_{u}$ is thickness and width of stand, $\mathrm{m}$.

Based on earlier researches, we accept angle of chisel blade sharpening $i_{i}=15^{\circ}$, angle of bit sharpening $i_{u}=30^{\circ}$, angle of chisel crushing $20^{\circ}$, chisel thickness and width $t_{y}=0,03 \mathrm{~m}$, and $b_{u}=0,18 \mathrm{~m}$ accordingly.

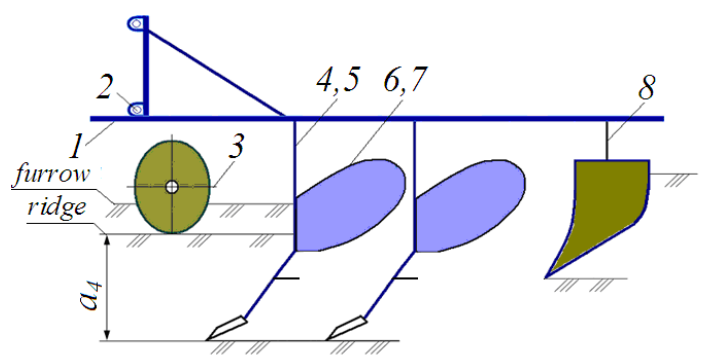

a)

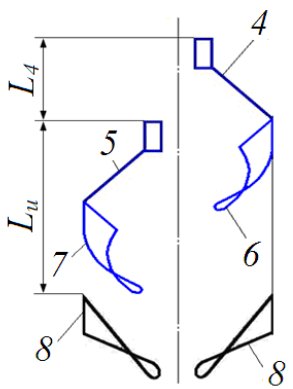

b)

Fig. 2. Structural scheme of the combined machine $(a)$ and arrangement of its working tools $(b): 1$ is frame; 2 is attachment; 3 is support wheel; 4 and 5 is deep loosener with tilt frame; 6 and 7 is left and right mouldboard; 8 is ridging tool 
The width of the deep loosener bit is determined based on the exclusion of the formation of growth in front of the bit according to the following expression proposed by V.Trufanov

$$
b_{i} \geq \frac{h_{c r}}{\mu}
$$

where $h_{c r}$ is the maximum working depth of the deep opener, $\mathrm{m} ; \mu$ is the coefficient expressing the ratio of the critical depth of the bit stroke to its width.

According to expression (1), at $h_{c r}=30 \mathrm{~cm}$ and $\mu=7,0$, bit width should be no less than $0,43 \mathrm{~m}$. We accept $b_{i}=0,05 \mathrm{~m}$.
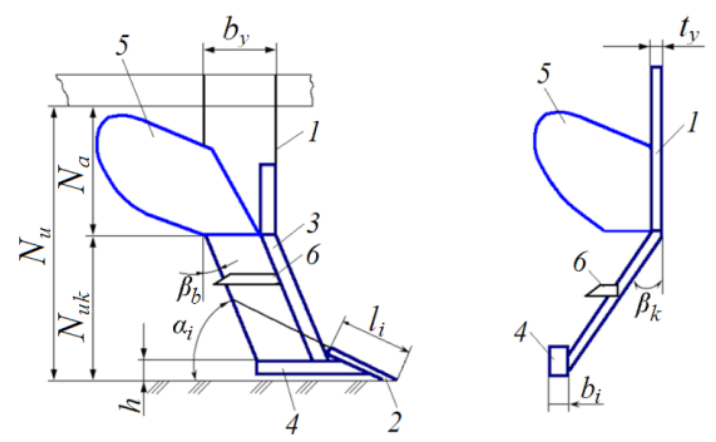

Fig. 3. Main parameters of the subsoiler: 1 is prop; 2 are chisels; 3 is blade; 4 is shoe; 5 is mouldboard; 6 is ripper

Chisel length of subsoiler shall be determined considering the condition of smooth soil slide on chisel working surface and sufficient breaking under its action by the following formula

$$
l_{i} \leq \frac{\left\{\frac{\sigma_{v r} \sin ^{2}\left(\frac{\pi}{2}+\frac{\alpha_{i}-\varphi_{1}-\varphi_{2}}{2}\right)}{\rho \sin \left(\frac{\pi}{2}-\frac{\alpha_{i}+\varphi_{1}+\varphi_{2}}{2}\right)}-\frac{V^{2} \sin \alpha_{i}}{g}\left[\sin \left(\frac{\pi}{2}+\frac{\alpha_{i}-\varphi_{1}-\varphi_{2}}{2}\right) \operatorname{tg} \varphi_{1}-\cos \left(\frac{\pi}{2}+\frac{\alpha_{i}-\varphi_{1}-\varphi_{2}}{2}\right)\right]\right\}}{\sin \alpha_{i} \sin \left(\frac{\pi}{2}+\frac{\alpha_{i}-\varphi_{1}-\varphi_{2}}{2}\right)+\sin \left(\frac{\pi}{2}-\frac{\alpha_{i}+\varphi_{1}+\varphi_{2}}{2}\right) \operatorname{tg} \varphi_{1}},
$$

where $\sigma_{v r}$ is temporary resistance of soil to shear, $\mathrm{Pa} ; \varphi_{1}$ and $\varphi_{2}$ is angle of external and internal friction of soil, degrees; $\rho$ is specific weight of soil, $\mathrm{kg} / \mathrm{m} 3 ; g$ is free-fall acceleration, $\mathrm{m} / \mathrm{s}^{2} ; V$ is speed of movement, $\mathrm{m} / \mathrm{s}$.

According to expression (2), at $\alpha_{i}=20^{\circ} ; v_{r}=2104 \mathrm{~Pa} ; \varphi_{1}=30^{\circ} ; \varphi_{2}=40^{\circ} ; \rho=1450 \mathrm{~kg} / \mathrm{m}^{3}$ and $V=2 \mathrm{~m} / \mathrm{s}$, length of chisel working surface should be $\ell_{i}=0,196 \mathrm{~m}$. We take $\ell_{i}=0,2 \mathrm{~m}$.

The height of the deep opener is determined by the following expression

$$
N_{u}=a_{p}-\frac{N_{p}-h_{n m}}{2}-a_{a}+\frac{l_{i} \sin \alpha_{i}}{2}+1.2 \sqrt{a_{a}^{2}+b_{a}^{2}}
$$

where $a_{n}$ is thickness of loosened soil layer relative to top of formed ridge, $\mathrm{m} ; H_{n}$ is height of new ridge, $\mathrm{m} ; h_{n m}$ is height of existing ridge, m. $a_{a}$ is depth of moldboard tillage, m.

By expression (9) at $a_{p}=0,45 \mathrm{~m}, h_{p m}=0.15 \mathrm{~m}, a_{a}=0.12 \mathrm{~m}, b_{a}=0.21 \mathrm{~m}, \ell_{i}=0.2 \mathrm{~m}, \alpha_{i}=30^{\circ}$, $l_{u}=0.26 \mathrm{~m}$ and $a_{\text {pmax }}=0.5 \mathrm{~m}$ height of subsoiler should be no less than $N=0,72 \mathrm{~m}$. We assume 
$N=0,72 \mathrm{~m}$.

The longitudinal distance between adjacent subsoilers is determined based on the conditions of avoiding overlapping of the zone of soil deformation by rear subsoiler chisel with the zone of soil deformation by front subsoiler chisel

$$
L_{c} \geq\left(a_{p}-N_{p}+\frac{1}{2} h_{n}\right) \operatorname{ctg} \psi_{1}
$$

At $a_{p}=0,45 \mathrm{~m}, h_{n}=0,15 \mathrm{~m}, l_{n}=0,26 \mathrm{~m}$, and $\psi_{1}=40^{\circ}$ by expression (7), the longitudinal distance between subsoilers should be no less than $0,375 \mathrm{~m}$.

The longitudinal distance from the deep loosener's chisel to the ridge loosener's chisel toe is determined based on the conditions of avoiding overlapping of the soil deformation zone by the chisel and the ridge loosener to each other

$$
L_{c u} \geq l_{i} \cos \alpha_{u}+N_{u k} \operatorname{tg} \beta_{b}+b_{a} \operatorname{ctg} \gamma_{a}+a_{p} \operatorname{ctg} \psi
$$

According to expression (8) at $l_{i}=0.2 \mathrm{~m}, \alpha_{\mathrm{i}}=20^{\circ}, \mathrm{N}_{\mathrm{uk}}=0.3 \mathrm{~m}, \mathrm{ba}=0.21 \mathrm{~m}, \gamma=40^{\circ}$, and $\psi=45^{\circ}$ longitudinal distance from deep loosener chisel to ridge former's nose should be no less than $0.63 \mathrm{~m}$.

Experimental researches on the justification of design of working elements of the developed unit and scheme of their mutual arrangement, scheme of arrangement of mouldboard deep loosener with sloping legs on the frame, length of wing and width of capture, width of capture, angle of crumbling and angle of installation of ripper blade to the direction of movement were carried out.

Experimental studies were conducted in two stages. At the first stage, the influence of the construction of working tools with a tilt stand and their mutual location, type of working tools for tillage of inter-row and ridge forming and their mutual location, the longitudinal distance between the mouldboard deep rippers with a tilt stand, number and width of ripper and also speed of their movement on their agricultural and energy performance were studied; at the second stage, the multi-factor experiments with the application of mathematical planning of experiments were carried out.

To conduct experimental research on the justification of the design of working tools with tilt legs and scheme of their mutual arrangement, four variants of experimental samples of working tools were developed and manufactured. The results of experimental studies showed that at speeds of 7-9 $\mathrm{km} / \mathrm{h}$ to ensure the required quality of crumbling the soil with minimal energy consumption is advisable to use in the unit working bodies with a tilted leg facing each other with their working surfaces and offset relative to each other in the longitudinal plane.

To conduct experimental research on the substantiation of the type of working elements for tilling between the rows and the forming of ridges and their relative positioning, the device consisting of different working elements was made of three variants. According to the research results, it was established that the device consisting of mouldboard deep loosening tools with angle legs and ridging tools ensures the formation of ridges with required height and minimum energy consumption.

According to the data of the one-factor experiments, it is established that the length of the wing of the subsoiler should be within 0.47-0.49 $\mathrm{m}$, and the width of the ripper should be within $0.1-0.14 \mathrm{~m}$ to provide the required quality of work with minimum power consumption at speeds of $7-9 \mathrm{~km} /$ hour and the longitudinal distance between them should be no less than $0.375 \mathrm{~m}$. 


\section{Conclusions}

1. The most optimal constructive scheme of combined aggregate is the scheme with consecutive installation of tilted subsoilers equipped with right- and left-turning mouldboards and ridge breakers.

2. It was established that to ensure the formation of new ridges instead of existing ones on fields without cotton stalks of required degree with minimum energy consumption working surfaces of inclined subsoilers equipped with mouldboards and rippers should face each other and shift relatively from each other in the longitudinal plane.

3. The formation of ridges to the required degree with minimum energy input is ensured when the width and length of the chisel respectively 5 and $20 \mathrm{~cm}$, width of the wing share $21 \mathrm{~cm}$, wing length between $47-49 \mathrm{~cm}$, the minimum longitudinal distance between subsoilers $35 \mathrm{~cm}$.

\section{References}

1. Mamatov, F.M., Eshdavlatov, E., Suyunov, A. The Shape of the Mixing Chamber of the Continuous Mixer // Jour of Adv Research in Dynamical \& Control Systems, Vol. 12, 07-Special Issue, 2020. DOI: 10.5373/JARDCS/V12SP7/20202318 ISSN 1943023X.

2. Mamatov, F., Ergashev, I., Ochilov, S., Pardaev, X. Traction Resistance of Soil Submersibility Type "Paraplau" // Jour of Adv Research in Dynamical \& Control Systems, Vol.12, 07-Special Issue, 2020. DOI: 10.5373/JARDCS/V12SP7/20202336 ISSN1943-023X.

3. Aldoshin, N., Mamatov, F., Ismailov, I., Ergashov, G. Development of combined tillage tool for melon cultivation // 19th international scientific conference engineering for rural development Proceedings, Jelgava, 20.-22.05.2020. Volume 19. ISSN 16915976. DOI:10.22616/ERDev.(2020).19.TF175.

4. Umurzakov, U., Mirzaev, B., Mamatov, F., Ravshanov, H., Kurbonov, S. A rationale of broach-plow's parameters of the ridge-stepped ploughing of slopes // XII International Scientific Conference on Agricultural Machinery Industry IOP Conf. Series: Earth and Environmental Science 403(2019) 012163 IOP Publishing doi:10.1088/1755-1315/403/1/012163.

5. Mirzaev, B., Mamatov, F., Chuyanov, D., Ravshanov, X., Shodmonov, G., Tavashov, $\mathrm{R}$ and Fayzullayev, $\mathrm{X}$. Combined machine for preparing soil for cropping of melons and gourds // XII International Scientific Conference on Agricultural Machinery Industry. doi.org/10.1088/1755-1315/403/1/012158.

6. Mirzaev, B., Mamatov, F., Ergashev, I., Ravshanov, H., Mirzaxodjaev, Sh., Kurbanov, Sh., Kodirov, U and Ergashev, G. Effect of fragmentation and pacing at spot ploughing on dry soils // E3S Web of Conferences 97. doi.org/10.1051/e3sconf/201913501065.

7. Mamatov, F., Mirzaev, B., Shoumarova, M., Berdimuratov, P., Khodzhaev, D. Comb former parameters for a cotton seeder// International Journal of Engineering and Advanced Technology (IJEAT) Volume-9 Issuel October/ DOI: 10.35940/ijeat.A2932.109119.

8. Mamatov, F., Mirzaev, B., Batirov, Z., Toshtemirov, S., Tursunov, O., Bobojonov, L. Justification of machine parameters for ridge forming with simultaneous application of fertilizers // CONMECHYDRO - 2020 IOP Conf. Series: Materials Science and Engineering 883(2020) 012165 IOP Publishing. doi:10.1088/1757899X/883/1/012165.

9. Mirzaev, B., Mamatov, F., Avazov, I., Mardonov, S. Technologies and technical means for anti-erosion differentiated soil treatment system // E3S Web of Conferences. 
doi.org/10.1051/e3sconf/20199705036.

10. Aldoshin, N., Didmanidze, O., Mirzayev, B., Mamatov, F. Harvesting of mixed crops by axial rotary combines // Proceeding of $7^{\text {th }}$ International Conference on Trends in Agricultural Engineering (2019). 17 th $^{\text {th }} 20^{\text {th }}$ Czech Republic. - pp.20-26. September (2019).

11. Mirzaev, B., Mamatov, F., Aldoshin, N and Amonov, M. Anti-erosion two-stage tillage by ripper// Proceeding of 7th International Conference on Trends in Agricultural Engineering 17th-20th. Czech Republic. - pp.391-396. September (2019).

12. Mirzaev, B., Mamatov, F., Ergashev, I., Islomov, Yo., Toshtemirov, B., Tursunov O. Restoring degraded rangelands in Uzbekistan // Procedia Environmental Science, № 6. - pp 395-404. (2019).

13. Uzakov, Z.U., Mamatov, F.M., Begulov, O. Implementation of object-oriented Programming technology in the one-dimensional oil displacement problem // International Conference on information Science and Communications Technologies: ICISCT 2019/0012008. Tashkent, Uzbekistan. INSPEC Accession Number: 19412491. DOI: 10.1109/ICISCT47635.2019.9012008.

14. Mamatov, F., Mirzaev, B., Berdimuratov, P., Turkmenov, Kh., Muratov, L., Eshchanova, G. The stability stroke of cotton seeder moulder // CONMECHYDRO 2020. IOP Conf. Series: Materials Science and Engineering 883 (2020) 012145 IOP Publishing. doi:10.1088/1757-899X/883/1/012145.

15. Mamatov, F., Mirzaev, B., Tursunov, O. A Justification of Broach-Plow's Parameters of the Ridge-Stepped Ploughing // E3S Web of Conferences 97, 05035 (2019). doi.org/10.1051/e3sconf/20199705035.

16. Ahmedov, B.J., Mirzaev, B.S.,Mamatov, F.M., Khodzhaev, D.A., Julliev, M.K. Integrating of gis and gps for ionospheric perturbations in d- And f-layers using vlf receiver // InterCarto, InterGIS 26, - c. 547-560. DOI: 10.35595/2414-9179-2020-1-26547-560.

17. Mamatov, F., Mirzaev, B., Tursunov, O., Ochilov, S and Chorieva, D. Relief, physicomechanical and technological properties of soil in the cotton growing area // ICECAE 2020. IOP Conf. Series: Earth and Environmental Science 614(2020) 012169. IOP Publishing. doi:10.1088/1755-1315/614/1/012169.

18. Shamsutdinov, Z., Ubaydullaev, Sh., Shamsutdinov, N., Mirzaev, B., Mamatov, F., and Chorshabiyev, N. The concept of the phytogenic field: theory, research experience and practical significance // ICECAE 2020. IOP Conf. Series: Earth and Environmental Science 614(2020) 012164. IOP Publishing. doi:10.1088/1755-1315/614/1/012164.

19. Umurzakov, U., Mamatov, F., Aldoshin, N., and Mirzaev, B. Exploration of tillage technologies in the Republic of Uzbekistan // ICECAE 2020 IOP Conf. Series: Earth and Environmental Science 614(2020) 012168. IOP Publishing. doi:10.1088/17551315/614/1/012168.

20. Mamatov, F., Aldoshin, N., Mirzaev, B., Ravshanov, H., Kurbanov, Sh and Rashidov, N. Development of a frontal plow for smooth, furless plowing with cutoffs // IPICSE 2020. IOP Conf. Series: Materials Science and Engineering 1030 (2021) 012135 IOP Publishing. doi:10.1088/1757-899X/1030/1/012135.

21. Mamatov, F., Mirzaev, B., Mirzahodzhaev, Sh., Uzakov, Z and Choriyeva, D. Development of a front plow with active and passive working bodies // IPICSE 2020. IOP Conf. Series: Materials Science and Engineering 1030 (2021) 012164. IOP Publishing. doi:10.1088/1757-899X/1030/1/012164.

22. Mamato, F.M., Eshdavlatov, E., Suyuno, A. Continuous Feed Mixer Performance //Journal of Advanced Research in Dynamical and Control Systems (JARDCS). Volume-12, 07-Spesia1 Issue, 2020. DOI: 10.5373/JARDCS/V12SP7/20202343. ISSN 1943-023X. 
23. Mamatov, F., Ergashev, I., Mirzaev, B., Pardaev, X, Chorieva, D. Research of the Penetration Process of the Frontal Plow // 2nd Bukittinggi International Conference on Education (BICED) 2020. Journal of Physics: Conference Series 1779 (2021) 012002. IOP Publishing. doi:10.1088/1742-6596/1779/1/012002.

24. Kodirov, U., Aldoshin, N., Ubaydullayev, Sh., Sharipov, E., Muqimov, Z and Tulaganov, B. The soil preparation machine for seeding potatoes on comb // CONMECHYDRO - 2020 IOP Conf. Series: Materials Science and Engineering 883(2020) 012143 IOP Publishing doi:10.1088/1757-899X/883/1/012143.

25. Ravshanov, Kh., Fayzullaev, Kh., Ismoilov, I., Irgashev, D., Mamatov, S. The machine for the preparation of the soil in sowing of plow crops under film // CONMECHYDRO - 2020 IOP Conf. Series: Materials Science and Engineering 883(2020) 012138 IOP Publishing doi:10.1088/1757-899X/883/1/012138.

26. Ravshanov, H, Babajanov, L, Kuziev, Sh, Rashidov, N, Kurbanov, Sh. Plough hitch parameters for smooth tails// CONMECHYDRO - 2020 IOP Conf. Series: Materials Science and Engineering 883(2020) 012139 IOP Publishing doi:10.1088/1757899X/883/1/012139.

27. Chuyanov, D., Shodmonov, G.,Avazov, I., Rashidov, N, Ochilov, S. Soil preparation machine parameters for the cultivation of cucurbitaceous crops // CONMECHYDRO - 2020 IOP Conf. Series: Materials Science and Engineering 883(2020) 012139 IOP Publishing doi:10.1088/1757-899X/883/1/012122.

28. Mamatov F.M., Mirzaev B.S., Avazov I.Zh.. Agrotehnicheskie osnovy sozdanija protivojerozionnyh vlagosberegajushhih tehnicheskih sredstv obrabotki pochvy $\mathrm{v}$ uslovijah Uzbekistana // - Prirodoobustrojstvo, 2014. [In Russian].

29. Mamatov F.M., Mirzaev B.S. Erosion preventive technology of crested ladder-shaped tillage and plow design // European Applied Sciences.- pp. 71-73. Stuttgart (Germany), (2014).

30. Lobachevskij Ja.P., Mamatov F., Jergashev I.T. Frontal'nyj plug dlja hlopkovodstva // - Hlopok, № 6. - 35-37 str. [In Russian]. (1991).

31. Kurdjumov V.I., E.S.Zykin. Jenergosberegajushhaja tehnologija poseva propashnyh kul'tur // Mehanizacija i

32. jelektrifikacija sel'skogo hozjajstva. - № 1. -S. 7-8. [In Russian] -(2007).

33. Fayzullayev, Kh, Mamatov, S, Radjabov, M, Sharipov, Sh, Tavashov, R and Nurmanova, M. The quality of loosening the soil with subsoilers of the combined machine // IPICSE 2020. IOP Conf. Series: Materials Science and Engineering 1030 (2021) 012171.IOP Publishing. doi:10.1088/1757-899X/1030/1/012171.

34. Temirov, I, Ravshanov, Kh, Fayzullaev, Kh, Ubaydullaev, Sh and Kodirov, U. Development of a machine for preparing the soil for sowing melons under the film // IPICSE 2020. IOP Conf. Series: Materials Science and Engineering 1030 (2021) 012169. IOP Publishing. doi:10.1088/1757-899X/1030/1/012169.

35. Rakhmonov S., Umurzakov U., Rakhmonov K., Bozarov I., Karamatov O. Land use and land cover change in Khorezm, Uzbekistan. E3S Web of Conferences, 227, 01002, (2021)

36. Umurzakov U., Mamatov F., Aldoshin N., Mirzaev B. Exploration of tillage technologies in the Republic of Uzbekistan, IOP Conference Series, Earth and Environmental Science, 614(1), 012168, (2020)

37. Umurzakov U., and Djuraev B. Prediction of prices for agricultural products through markov chain model, International Journal of Psychosocial Rehabilitation, 24(3), pp. 293-303, (2020)

38. Umurzakov U., Mirzaev B., Salahodjaev R., Isaeva A., and Tosheva S. Energy consumption and economic growth: Evidence from post-communist countries. International Journal of Energy Economics and Policy, 10(6), pp. 59-65, (2020) 